\title{
Transitivity Analysis of Gabriel Okara's The Voice
}

\author{
Nouréni Boukari $^{1^{*}}$, Léonard A. Koussouhon ${ }^{2}$ \\ ${ }^{I}$ Department of English, University of Parakou, 02 BP 131 Parakou, Republic of Benin. \\ ${ }^{2}$ University of Abomey-Calavi (UAC), Benin
}

\begin{abstract}
*Corresponding Author: Nouréni Boukari, Department of English, University of Parakou, 02 BP 131 Parakou, Republic of Benin
\end{abstract}

\begin{abstract}
This article is meant to point out the overall message conveyed in Gabriel Okara's novel, The Voice (1964). Based on Systemic Functional Linguistics, the article focuses on the investigation of the ideational meaning by looking into the transitivity patterns. Examining two key extracts under such a linguistic-stylistic angle will contribute with enough scientific evidence to revealing that, indeed, as may be noticed by any reader (ordinary readers and scholars alike), the main character Okolo's "search for it" is the main topic that runs along most pages of the literary artifact under study. From the investigation of the different process types that occur in the selected text, one can realize that it is all about man's perpetual need to always take action, to understand the meaning of life, to set a fair society and to reach salvation.
\end{abstract}

Keywords: The Voice, Transitivity Patterns, Ideational Meaning, Meaning of Life, Salvation

\section{INTRODUCTION AND LITERATURE REVIEW}

The Voice, written by Nigerian Gabriel Okara in 1964, has been subject to much literary criticism. For instance, as Ashaolu (1979, p.111) puts it in his introductory paragraph, curious parallels have been drawn between Okolo (the central character in The Voice) and a number of other literary characters. According to Ashaolu, Anozie (1965) sees Okolo in the light of Hamlet seeking to get to the "bottom" of things, but having to run his head against the wall constituted by the usurping King Cladius. Anozie also identifies in The Voice thematic echoes from Conrad's Victory and claims that the tragedy of Okolo is comparable to that of Axel Heyst. Palmer (1972) likens Okolo to Christian in Bunyan's The Pilgrim's Progress and to Man in Armah's The Beautiful Ones Are Not Yet Born because all these characters in their search for salvation "play symbolic roles, representing forces and ideas much larger than themselves." Palmer goes further to recognize in Okolo's quest something of the search for Holy Grail in Eliot's "The Waste Land." He then compares Okolo's persecution in Sologa with that of Clarence in Part I of Camara Laye's The Radiance of the King, and finds in Okolo the picaresque heroic qualities of Don Quixote. Still in Ashaolu's introductory paragraph, in the last sentence, he points out that Obiechina (1972) virtually makes a Christ of Okolo in an attempt to establish the presence of all the main stages of the Passion story in Okolo's life.

Thumboo (1986) opines that The Voice succeeds in a special sense: "Okara's consistent and sustained orchestration of English compels the reader to enter his mode and learn its meaning - procedures linked into strategies that form the basis of a narrative that takes us gradually deeper into the fuller significance of his theme..." Scott (1990), also concerned with the language used in The Voice, provides an interesting stance on the relation between African authors and the colonial linguistic legacy by examining the text's "translingual feature". Vakunta (2010) points out that Okara's style of writing produces a variety of English in which idiom and syntax are radically altered. He further argues that the English we read in this novel is not standardized but domesticated English that constantly suggests the presence of another tongue. According to him, this double-voicedness is the quality that makes Okara's fiction unique and challenging to the uninformed reader.

While all these works of criticism are purely literary, the present paper belongs to the category of linguistic stylistic analysis. It looks at ideational meaning in the novel, based on Halliday's transitivity framework. 
In one of the first analyses of this type, Halliday (1971) explores the patterns of transitivity which occur in the clauses of The Inheritors and shows how they illustrate the control of the world by human beings who dominate one another. Kies's (1992) analysis of George Orwell's Nineteen eighty-four is based on the identification and description of the main linguistic features in that literary artifact. $\mathrm{He}$ eventually explains away the devices through which the thoughts and action of a totalitarian statesman are weakened by the power of the state. Iwamoto's (2007) synoptic account of Systemic Functional Grammar focuses on transitivity theory and Ergative analysis, two similar methods of linguistic investigation. By applying both techniques, he expands Carter's (1997) analysis of the "Cinderella story"; indeed his study sheds light on gender issues as addressed in the story under consideration.

In Koussouhon's (2009) analysis of The Beautiful Ones Are Not Yet Born by Ayi Kwei Armah, he draws our attention to the contrast between the abundance of material processes and the lack of Causatives in the texts studied. He points out that the human participants who play the role of Actor in those material processes seem to be in a roundabout and that their togetherness does not yield any productive actions. The lack of Causative processes, he argues, points to the evidence that nobody gets anybody to do anything in order to bring about a change in the novel world. The analyst's final interpretation of his findings is that the excerpts - and probably the whole novel - depict a world of ineffectuality and pessimism [...] which is "Ghana's or Africa's lot as viewed by Ayi Kwei Armah". Such interpretation is not far-fetched and fantasy-oriented; it is actually based not only on the occurrence of foregrounding in the texts but also on verbalization and symbolic articulation leading to the formulation of verbal art. At least there is hardly any doubt that the analyst has in mind the verbal art in the text as he interprets his findings. Also, Koussouhon's (2008) reassessing of the language of "Abiku" is an application of both register and transitivity analyses to poetic texts. He has come up with systemic linguistic-based evidence of similarities and differences between Soyinka's and Clark's use of language even when they are conveying almost the same message.

A great part of Boukari's (2015) investigation of meanings in Flora Nwapa's novels is devoted to transitivity pattern analysis as well. It has led to the inferring of the ideational meaning conveyed in the studied novels, which includes, among others, women's search of emancipation and (some) men's irresponsibility towards their wives or concubines. True, the dissertation includes a lengthy interpretation of findings, but it is confined to the Hallidayan framework and does not seem to reach the stratum of theme(s) from the perspective of verbal art.

Without dwelling on pioneering investigations, the theory of Transitivity is explained in the following section, and the research methodology is specified as well (section 4). Next comes the analysis proper (section 5).

\section{TRANSITIVITY MODEL}

Devised and elaborated by M. A. K. Halliday (1985) and his colleagues (Hasan 1985, Eggins 1994/2011, Matthiessen 2004...), Systemic Functional Linguistics studies language as a system of meanings. The theory holds that human language depends on three Register Variables (Field, Tenor, Mode) and that it involves meaning on three levels: the experiential, the interpersonal and the textual. The experiential or ideational meaning is based on the field of discourse and it relates to the "transmission of ideas", implying the main topic(s) which the text is about. The interpersonal meaning, which depends on the tenor of discourse, concerns interaction. Based on the mode of discourse, the textual meaning is about the organization of the conveyed message. Moreover, the experiential meaning is realized through the lexico-grammatical patterns of Transitivity, the interpersonal meaning through the Mood patterns and the textual meaning through Theme patterns. This paper is specifically concerned with the transitivity analysis; reason why the theory of transitivity is worth recalling here.

The analysis of transitivity patterns consists in identifying and trying to account for the occurrence of the different process types, the participants in the clauses and the circumstances. As Eggins (1994), quoted by Koussouhon (2009 b, p.129), puts it, "the different kinds of processes constitute the major system which expresses the meaning of any clause which determines the role of the associated participants occurring in different configurations". Processes themselves are expressed by verb phrases in clauses. There are six (06) process types: in fact, a transitivity process may be material, mental, verbal, behavioural, existential or relational, respectively according to whether it represents a process of doing, sensing, saying, behaving, existing or being. Each type is explained below. 


\subsection{Material Processes}

Material processes are processes of doing. As specified by Iwamoto (2007:70), they are processes of doing "in the physical world". A material process has two inherent participants involved in it: the Actor and the Goal. The Actor is an obligatory element as it expresses the doer of the process. The Goal, which expresses the person or entity affected by the process, is an optional element, rather called Range when it is a restatement of the process. In addition, there is an element called Circumstance, which may also occur with material processes and, in fact, with any other process types. The Circumstancial meaning is realized by adverbial groups or prepositional phrases to notify when, where, how and/or why the process takes place. There are seven types of Circumstance: Extent (which may express duration or distance), Cause (expression of reason, purpose or behalf), Location (which may express time or place), Matter, Manner, Role and Accompaniment.

Here are three examples ("Pr" stands for "Process" and "Circ" for "Circumstance"):

\begin{tabular}{|l|l|l|l|l|}
\hline \multirow{2}{*}{$(1)$} & The carpenter & took & the hammer & from the large table \\
\cline { 2 - 5 } & Actor & Pr: material & Goal & Circ: location \\
\hline \multirow{2}{*}{$(2)$} & The exhausted athlete & fell over & before the end of the race \\
\cline { 2 - 4 } & Actor & Pr: material & Circ: location \\
\hline
\end{tabular}

\begin{tabular}{|l|l|l|l|l|}
\hline$(3)$ & The door & hit & the wall & very noisily \\
\hline & Actor & Pr: material & Goal & Circ: manner \\
\hline
\end{tabular}

Indicating Berry (1977) and Halliday (1976) as sources for details, Iwamoto (pages 71 and 94) notifies that "material processes can be further subclassified according to whether the process is performed intentionally or spontaneously and whether by an animate Actor or inanimate Actor". In fact, a material process performed by an animate Actor is called Action process, like (1) and (2) above. One performed by an inanimate Actor is rather referred to as Event process, like (3) above. Action processes can be further divided into Intention process and Supervention process. Intention process means one in which the animate Actor performs intentionally - like (1) above - whereas Supervention process is one in which "the process just happens to the Actor without his or her intention" - like (2) above.

\subsection{Mental Processes}

Mental processes encode the meanings of thinking or feeling. As reported by Iwamato (page 78), Simpson (1993: 91) calls them "internalized" processes, in contrast to the "externalized" processes of doing and speaking. A mental process involves two participants: Senser and Phenomenon. The Senser is the participant who performs the process of feeling, thinking or perceiving. Only conscious beings play this role. What is felt, thought or perceived is Phenomenon. Mental process verbs are subcategorized by Halliday into three types: Cognition (verbs of thinking, knowing, understanding), Affection (verbs of liking, loving, fearing, hating), and Perception (verbs of seeing and hearing). Here are three examples:

\begin{tabular}{|c|c|c|c|}
\hline Cognition: (4) & Few people & understand & that theory \\
\hline & Senser & Pr: mental & Phenomenon \\
\hline Affection: (5) & I & love & that lady \\
\hline & Senser & Pr: mental & Phenomenon \\
\hline
\end{tabular}

\begin{tabular}{|l|l|l|l|}
\hline Perception: (6) & I & heard & her voice \\
\hline & Senser & Pr: mental & Phenomenon \\
\hline
\end{tabular}

\subsection{Verbal Processes}

Verbal processes are processes of verbal action, such as "say, tell, speak, talk, ask...". They usually involve three participants: Sayer, Verbiage and Receiver. The Sayer is the participant responsible for the verbal process. What is said is called Verbiage and the one to whom it is addressed is known as Receiver. Here are three examples:

\begin{tabular}{|l|l|l|l|l|l|}
\hline$(7)$ & She & told & us & her name & hesitantly \\
\hline & Sayer & Pr: verbal & Receiver & Verbiage & Circ: manner \\
\hline
\end{tabular}




\begin{tabular}{|c|c|c|c|}
\hline (8) & She & said & her name is Sarah \\
\hline & Sayer & Pr: verbal & Verbiage \\
\hline \multirow[t]{2}{*}{ (9) } & She & said & "My name is Sarah" \\
\hline & Sayer & Pr: verbal & Verbiage \\
\hline
\end{tabular}

As (8) and (9) respectively show, the Verbiage part may be either indirectly reported or directly quoted.

\subsection{Behavioural Processes}

Essentially, behavioural processes are processes of physiological and psychological acts. They are expressed with such verbs as "breathe, cough, cry, dream, frown, laugh, listen, look at, sigh, smile, sniff, snuffle, stare, taste, watch...". The one involved in the process of committing such acts is called Behaver. When the process is directed to one entity, whether human, animate or inanimate, that entity is called Phenomenon. Of course, the Phenomenon will rather be called Behaviour when it is like Range (a restatement of the process); that is the case in (11) below.

\begin{tabular}{|l|l|l|l|l|}
\hline$(10)$ & The woman & looked at & her assailants & angrily \\
\hline & Behaver & Pr: behavioural & Phenomenon & Cicr: manner \\
\hline$(11)$ & David & smiled & a broad smill \\
\hline & Behaver & Pr: behavioural & Behaviour \\
\hline
\end{tabular}

\subsection{Existential Processes}

Existential processes encode meanings about states of being as entities of any kind are stated to exist. The structure of existential process clauses involves the use of the structural "there" which has no representational meaning although it is necessary as a subject. So, the structural "there" receives no functional label and it is left unanalyzed for transitivity. Only the other constituents are labelled: the verb "be" or synonyms such as "exist, arise, occur", plus an obligatory participant which is called the Existent. Here is an example:

\begin{tabular}{|l|l|l|l|l|}
\hline$(12)$ & There & is & no-one & in the bathroom \\
\hline & & Pr: existential & Existent & Cicr: location \\
\hline
\end{tabular}

\subsection{Relational Processes}

There are two main types of relational processes: attributive relationals and identifying relationals. Each of these two types may be intensive, circumstantial or possessive.

An intensive relational is one through which a relationship is established between two terms with the use of the verb "be" or a synonym. If it is an Attributive intensive, a participant called Carrier is assigned a quality, qualification, or descriptive epithet which is called the Attribute. So, Carrier and Attribute are the two obligatory participants of an Attributive intensive, and the meaning of the relationship between them is that "participant $x$ is a member of the class of participant $y$ ". Here are three examples:

\begin{tabular}{|l|l|l|l|l|}
\hline \multirow{2}{*}{$(13)$} & Very few people & are & honest & nowadays \\
\cline { 2 - 5 } & Carrier & Pr: intensive & Attribute & Circ: location \\
\hline \multirow{2}{*}{$(14)$} & Okara & is & a great writer \\
\cline { 2 - 5 } & Carrier & Pr : intensive & Attribute \\
\hline \multirow{2}{*}{$(15)$} & Hasan and Eggins & could have been & friends \\
\cline { 2 - 4 } & Carrier & Pr: intensive & Attribute \\
\hline
\end{tabular}

Although the most common intensive verb used in English is "be", some intensive Attributive synonyms are often used as well. Those verbs include: "appear, become, end up, feel, grow, keep, look, remain, seem, smell, sound, stand, stay, taste, turn...". Here is an example:

\begin{tabular}{|l|l|l|l|l|}
\hline \multirow{2}{*}{$(16)$} & The desperate woman & remained & quiet & for hours \\
\cline { 2 - 5 } & Carrier & Pr: intensive & Attribute & Circ: extent \\
\hline
\end{tabular}


Intensive Identifying processes are not about ascribing or classifying. Instead, they are defining. In such processes, there are two compulsory participants: a Token and a Value. The participant that stands for what is being defined is Token and the one that defines is Value. The relationship between the two participants is that one serves to define the identity of the other. Here is one example:

\begin{tabular}{|l|l|l|l|}
\hline \multirow{2}{*}{$(17)$} & Adam & is & my best friend \\
\cline { 2 - 4 } & Token & Pr: intensive & Value \\
\hline
\end{tabular}

Contrary to Attributive clauses, Identifying clauses are reversible without any syntactic or semanticrelated risks. For an illustration, we have a fully acceptable clause in reversing the example that has just been given.

\begin{tabular}{|l|l|l|l|}
\hline \multirow{2}{*}{$(18)$} & My best friend & is & Adam \\
\cline { 2 - 4 } & Value & Pr: intensive & Token \\
\hline
\end{tabular}

That is why Eggins (1994:260) writes that Token will always be Subject in an active clause and Value will always be Subject in a passive clause. In addition to "be", other intensive Identifying verbs include "define, equal, indicate, mean, refer to, represent, signify, stand for, suggest, symbolize ...", as shown in the following example:

\begin{tabular}{|l|l|l|c|}
\hline \multirow{2}{*}{$(19)$} & U.S. & stands for & "United Stated" \\
\cline { 2 - 4 } & Token & Pr: intensive & Value \\
\hline
\end{tabular}

Regarding circumstantial relational processes, they encode meaning about the circumstantial dimensions which are location, manner, matter, etc. In an Attributive Circumstantial, the Circumstance may be expressed in the Attribute or encoded in the process itself. Here are two examples:

\begin{tabular}{|c|c|c|c|}
\hline \multirow[t]{2}{*}{ (20) } & All his money & was & in his wallet \\
\hline & Carrier & Pr: intensive & Attribute / Circ: location \\
\hline \multirow[t]{2}{*}{ (21) } & That narrative & concerns & the latest operation \\
\hline & Carrier & Pr: circumstantial & Attribute \\
\hline
\end{tabular}

Possessive processes encode meaning of ownership and possession between participants. The most common Attributive possessive verbs are "to have" and "to belong to", with the Carrier as a possession then, as in this example:

\begin{tabular}{|l|l|l|l|}
\hline (22) & My friend & has (got) & a nice car \\
\hline & Carrier / Possessor & Pr: possessive & Attribute / Possessed \\
\hline
\end{tabular}

At last, Causative (relational) processes may occur with either Attributive or Identifying structures. As with the causative material processes, causative relationals involve an Agent in making or causing something, as illustrated in the example below:

\begin{tabular}{|l|l|l|l|l|}
\hline$(23)$ & That man's death & made & everyone & desperate \\
\hline & Agent / Attributor & Pr: causative & Carrier & Attribute \\
\hline
\end{tabular}

The transitivity model having been thus recalled, the methodology followed in this research needs to be specified as well.

\section{Synopsis of The CONTEXT AND CONTENT OF THE VoICE}

Gabriel Okara, known as a poet, has published only one novel, The Voice (1964), which is to be counted as one of Nigerian post independence novels. This novel depicts a number of social vices in the post independent Nigerian society, especially the social and political corruption, nepotism, injustice, to name but a few.

In fact, The Voice is the story of one man called Okolo (the protagonist), who returns from his studies abroad and finds himself completely alienated as he tries to be upright. His hometown is Amatu. Chief Izongo (the chief of this town) and his followers are all corrupt. There is merciless opposition between Okolo and the leaders. He believes that people should be only good-natured, honest and upright. He daily seeks the truth and the meaning of life, which he keeps calling "it" everyday and everywhere throughout the novel. As Chief Izongo and the elders feel threatened by his attitude, they say he is mad and they decide to ostracize him. Okolo's search for the meaning of life proves vain not only in his hometown Amatu but also in Sologa where he has gone when ostracized. 
The way the English language is used to relate such a story and convey meaning is analysed in this paper. The methodology followed in the paper is specified below.

\section{Methodology}

To apply the above Transitivity Model to The Voice, two extracts have been chosen from this 127page novel. Extract 1 goes from page 76 to page 78 and Extract 2 from page 111 to page 112. The first extract relates Okolo's travel by canoe to Sologa as he is chased away from his own village Amatu. The second extract relates his (Okolo's) continued search for and reflection over the meaning of life even when he reaches Sologa. My application consists in splitting each sentence into its (numbered) clauses and then each clause into constituents, as broadly shown in both texts displayed in the Appendix. The linguistic features at stake, i.e. transitivity patterns, are identified, counted and encoded in tables of statistics for the sake of quantitative analysis. The identified patterns are accounted for and the implications of meaning are spelt out in the section of Discussion.

\section{Data Analysis}

\subsection{The Main Transitivity Pattern Statistics in Both Extracts}

The task of identifying transitivity patterns in each extract results in the following two tables of statistics.

Table1. Process type distribution in both excerpts

\begin{tabular}{|c|c|c|c|c|c|c|c|}
\hline \multirow{2}{*}{\multicolumn{2}{|c|}{ Process types }} & \multicolumn{3}{|c|}{ Excerpt 1} & \multicolumn{3}{|c|}{ Excerpt 2} \\
\hline & & \multicolumn{2}{|c|}{ Number } & Percentage & \multicolumn{2}{|c|}{ Number } & Percentage \\
\hline \multicolumn{2}{|c|}{ Material processes } & & 77 & $72.64 \%$ & \multicolumn{2}{|c|}{21} & $28.37 \%$ \\
\hline \multicolumn{2}{|c|}{ Mental processes } & & 12 & $11.32 \%$ & \multicolumn{2}{|c|}{14} & $18.91 \%$ \\
\hline \multicolumn{2}{|c|}{ Verbal processes } & & 2 & $01.88 \%$ & \multicolumn{2}{|c|}{04} & $05.40 \%$ \\
\hline \multicolumn{2}{|c|}{ Behavioural processes } & & 9 & $08.49 \%$ & & & $01.35 \%$ \\
\hline \multicolumn{2}{|c|}{ Existential processes } & & 0 & $00 \%$ & \multicolumn{2}{|c|}{02} & $02.70 \%$ \\
\hline \multirow{4}{*}{$\begin{array}{l}\text { Relational } \\
\text { processes }\end{array}$} & Attributive & 05 & \multirow{4}{*}{06} & \multirow{4}{*}{$05.66 \%$} & 12 & \multirow{4}{*}{32} & \multirow{4}{*}{$43.24 \%$} \\
\hline & Identifying & 00 & & & 09 & & \\
\hline & Circumstantial & 00 & & & 06 & & \\
\hline & Possessive & 01 & & & 05 & & \\
\hline & TOTAL & & 106 & $100 \%$ & & & $100 \%$ \\
\hline
\end{tabular}

Table2. Circumstances in both excerpts

\begin{tabular}{|l|c|c|c|c|}
\hline \multirow{2}{*}{ Circumstances } & \multicolumn{2}{|c|}{ Excerpt 1 } & \multicolumn{2}{c|}{ Excerpt 2 } \\
\cline { 2 - 5 } & Number & Percentage & Number & Percentage \\
\hline Location & 20 & $57.14 \%$ & 10 & $50 \%$ \\
\hline Manner & 14 & $40 \%$ & 06 & $30 \%$ \\
\hline Extent & 01 & $02.85 \%$ & 01 & $05 \%$ \\
\hline Matter & 00 & $00 \%$ & 02 & $10 \%$ \\
\hline Cause & 00 & $00 \%$ & 01 & $05 \%$ \\
\hline Role & 00 & $00 \%$ & 00 & $00 \%$ \\
\hline Accompaniment & 00 & $00 \%$ & 00 & $00 \%$ \\
\hline
\end{tabular}

\section{About the statistics related to Excerpt 1}

As Table 1 shows, various process types occur in Excerpt 1, but material processes rank first. In fact, out of a total of one hundred and six (106) processes, seventy-seven (77) are material processes, representing $72.64 \%$ of the total; that is the highest process type occurrence rate in this text. The predominance of this process type means that the text is essentially concerned with concrete and tangible actions. Mental processes, though much less frequent than material ones, rank second: $12 / 106$, which makes $11.32 \%$. This relatively significant percentage of mental processes shows the text is somehow concerned with mental reactions as well. There are nine (09) behavioural processes, that is $08.49 \%$ of the total number of processes, which makes behavioural processes rank third. The occurrence of this process type indicates that some psychological or physiological actions are performed in the text. Relational processes rank fourth in the excerpt [06/106 (05.66\%)], but almost all of them (05/06) are attributive processes. So, the text is also concerned with describing participants. The only relational process which is not attributive is rather a possessive one. As to 
identifying and circumstantial processes, there are none. Verbal processes rank fifth as there are only two (02) of them (02/106), making $01.88 \%$ of the total. This suggests that the text is hardly concerned with verbal description or performance of action and events. We have $00 \%$ of existential processes, which means that the excerpt does not contain any existential process at all.

As Table 2 shows, three types of Circumstances are part of clause constituents in Excerpt 1: Location, Manner and Extent. Location is the most predominant type of Circumstance as it represents $57.14 \%$ of the total number of Circumstances in the excerpt. This predominance means that for most processes that take place in the text under consideration, the when (moment) and/or the where (place) is specified. Manner ranks second, representing $40 \%$ of the total number of Circumstances. This high proportion suggests that in many cases, the how is specified to further clarify the way things happen. There is only one Circumstance of Extent, which represents $02.85 \%$ of the total number, but there are not any Circumstances of Matter, Cause, Role and Accompaniment at all (00\%). So, in addition to the fundamental information "who does what (to whom)" provided in the various processes, Excerpt 1 is also concerned with indicating when, where and how. As to the Circumstances that should provide such additional information as what about (Matter), why / what for / who for (cause), what as (Role) and with whom (Accompaniment), they are totally non-existent in the excerpt.

\section{About the statistics related to Excerpt 2}

Regarding Excerpt 2, Table 1 shows that it too contains various and even all types of processes. However, we can notice a very large difference among the proportions of occurrence. Here, relational processes rank first. There are thirty-two (32) relational processes out of seventy-four in total, which makes $43.24 \%$. The thirty-two relational processes comprise all the four subtypes as follows: $12 / 32$ are attributive processes, 09/32 are identifying processes; 06/32 are circumstantial processes and $05 / 32$ are possessive processes. The predominance of relational processes so diversified suggests that the text is concerned with establishing relationships between entities in clauses, especially by describing some participants (through the 12 attributive processes), by defining other participants (through the 09 identifying processes), by describing or defining some entities (through the 06 circumstantial processes) and also by encoding possession (through the 05 possessive processes). Material processes rank second here, in Excerpt 2: 21/74, that is, $28.37 \%$. This shows that the excerpt is also concerned with concrete and tangible actions. Mental processes rank third, as the text contains $14 / 74$ such processes making $18.91 \%$ of the total. That is the proof that mental reactions are at stake as well. There are few verbal processes $(04 / 75$ or $05.40 \%)$, which suggests that the text is concerned with verbal description or performance of actions and events, but not much. There are even fewer existential processes [02/74 (02.70\%)] and behavioural processes [01/74 (01.35\%)]. From these very low proportions of occurrence, it can be inferred that the text is not considerably concerned with showing the existence of specific entities, neither is it noticeably concerned with psychological or physiological actions.

From the last two columns of Table 2, we can realize that most types of Circumstances occur as part of clause constituents in Excerpt 2: Location, Manner, Extent, Matter and Cause. Only two types (Role and Accompaniment) are missing. Circumstances of Location rank first by representing 50\% of the total number of Circumstances. This suggests that the specification of the moments and /or places is a priority in the text. Next, in second position comes the proportion of Circumstances of Manner: $30 \%$. This relatively important percentage shows that the how is specified as additional information to further indicate the way processes are often achieved throughout the text. There are two Circumstances of Matter (making 10\% of the total), one Circumstance of Extent (making 05\%) and also one Circumstance of Cause (making $05 \%$ as well). This means that the question "what about" has been answered to provide additional information to process types and main participants only in two clauses. It also means that the question "how far / how long / how often" has been answered to provide additional information only in one clause. It further suggests that the question "why" has been answered to provide additional information in one clause only. By contrast, the complete lack of Circumstances of Role and Accompaniment provides evidence that nowhere in any clause of the text has there been additional information to answer the question "What as?" or "With whom?"

The statistical description made so far helps to pave the way for a qualitative analysis of transitivity in both extracts. Therefore, the detailed analysis which consists in looking into the processes and their 
associated participants is carried out in the following sections, along with personal comments or arguments.

\subsection{Detailed Analysis of Process Types, Participants and Circumstances in Extract 1}

The numerous material processes in this extract (making $72.64 \%$ of the total) include both Action processes such as "he was lying on a floor" (clause 2, where "he" refers to Okolo) and Event processes such as "the light also moved back" (clause 34). It means that there are animate Actors and inanimate Actors at a time. In fact, in the 77 material processes, the role of Actor is distributed among:

- Okolo, as in clauses 2, 3 and 10;

- his thoughts, as in clauses 15,18 and 19 ;

- parts of his (Okolo's) body, as in clauses 16, 28 and 30;

- the light, as in clauses 34,36 and 38 ;

- and miscellaneous types of Actors from clause 82 to the end.

Okolo plays most of the Actor role in the Action processes. Now those Action processes include the subtype of Intention processes and Supervention processes as well. The Intention processes occur, for example, in "He drew his feet with all his soul" (clause 27), "He drew his hands" (clause 29), "He stood up with his eyes on the light (clause 31) and such other clauses as 32, 33 and 35. This presence of Intention processes, with Okolo as almost the sole Actor, shows that the text is concerned with a human participant engaged in actions, especially taking intentional actions for some purpose(s). Supervention processes occur in "he was lying on a floor" (clause 2, "he" referring to Okolo), "Okolo lay still in the darkness" (clause 10), "and (he/Okolo) fell" (clause 62) and other clauses such as 3, 21 and 22. Their occurrence suggests that the human participant at work does not only undertake intentional actions; instead, he often undergoes some actions that just happen to him without his intention. There are many Event processes and it is in those Event processes that the role of Actor is assigned to Okolo's thoughts, parts of his body and the light. The fact that the human participant's thoughts are assigned the role of Actor indicates that his mind is somehow in activity. The same goes for parts of his body also playing the role of Actor; his fect in clauses 28 and 50, his hands in clause 30 , his fingers in clauses 47,49 and 58. Such a scene of a participant lying with his thoughts and body parts, especially his limbs in diverse actions, conjures up the situation of a living being that is struggling, fighting hopefully or desperately, probably seeking to reach an objective. Regarding the light in the role of Actor, one is tempted to ask: who makes it move? Finding no agent, one may further ask: what kind of light is it anyway and how come that it moves by itself? An attempt of answer to this question will be provided later. As for the various Actors in the material process clauses $n^{\circ} 82$ through the end, they include "the crowd (clause 82), cars (clause 83), beggars (clause 87), priests (clauses 93 and 97)" to name but a few. This distribution of the role of Actor suggests that the text is concerned with the world as one can figure out, with many possible events that are likely to happen on this earth.

Out of the seventy-seven material processes in Excerpt 1, fifty-two (that is 67.53\%) are middle, i.e. intransitive, and twenty-five (that is $32.47 \%$ ) are effective, i.e transitive. So, there are many more middle processes than effective ones. The middle processes include "he (Okolo) is lying on a cold floor" (clause 2) - the process of lying being repeated in several other clauses, "and his feet came" (clause 28), "and his hands came" (clause 30), "He moved faster" (clause 35), "Okolo ran" (clauses 37,39 and 41)... It means that a large part of the text consists of material processes in which there are no participants playing the role of Goal. It is a situation in which, although there are a lot of actions of doing, you can't find on whom or on what the actions are done. Yet, the place is indicated most of the time. The frequent indication of the place where those actions take place is the reason why there is a large percentage of Circumstances of location. However, it is noteworthy that the place is almost invariably the same: on the cold floor (as in clauses 2, 3 and 21), in the darkness/inside (as in clauses 10 and 12). This suggests that the doer of the tangible actions is hardly taken from one place to another by those actions. The way in which most of the actions are done is shown through the use of 
Circumstances of Manner, such as "with his eyes as soft" (clause 21), "with all his soul" (clause 27) and "with his eyes on the light" (clause 31). The frequent occurrence of the Circumstances of Manner contributes to showing how hard the Actor is fighting.

Regarding the mental processes, here are seven of the twelve that I have identified in the text:

- When Okolo came to know himself (clause 1)

- but nothing he saw (clause 6)

- $\quad$ nothing he saw (clause 7)

- but his vision only met a rock-like darkness (clause 14)

- Then suddenly he saw a light (clause 26)

- He saw a light in front of him (clause 70)

- Okolo found himself (clause 76)

The role of Senser is played by the same human participant in all those clauses: Okolo. The mental process in the first clause is cognitive whereas the one in the other clauses ("saw") is perceptive. The process of seeing is repeated in most of those perceptives because the central character (who plays the role of Senser here) is fighting, as it were, against the darkness. The fighter is pushed into the limelight not only in the role of Senser in most clauses, but also in the role of Phenomenon ("himself") in clauses 1 and 76. This suggests that he is indeed the only one engaged in this fight and he can't find anyone by his side. The occurrence of "a light" in the role of Phenomenon in some clauses contributes to showing that this is the immediate objective of the fight. In fact, the light represents the truth. The process of seeing nothing (clauses 6 and 7) and "his vision only meeting a rock-like darkness" (clause 14) imply that it is really very difficult to find out the truth as Okolo intends to. When you set out to seck for the truth as this character (Okolo) does, you risk spending most of your time in the darkness.

The behavioural processes include, among others:

- He opened his eyes (clause 4, "He" referring to Okolo);

- at the rock-like darkness staring (clause 25);

- Okolo looked (clause 43);

- People laughing (clause 90).

The role of Senser is assigned to Okolo in most of those behairoural processes. The eyes opening process, which occurs in clauses 4 and 13, expresses some hope. The hope is further expressed through the process of staring, which occurs in such clauses as 23 and 25 with "rock-less darkness" as Phenomenon. The behavioural processes of opening his eyes, looking and staring insistently suggest that it is a challenge for the protagonist to brave the darkness which characterises our life. Some time, as he seems to have overcome the darkness, he finds a whole spectacle before him. Here, the process of watching continues because the world appears like a strange thing to him now. He can find people laughing (clause 90) but he is not sure whether their laughter is deep, sincere. So, watching the crowd (behavioural process in clause 101) may not be a sign of admiration but an expression of utmost surprise at how the world functions.

The few relational processes, such as "the darkness was evil darkness" (clause 8) and "the outside night was black night" (clause 9) contribute to showing the intensity of the darkness, say, of the obstacle, faced by the protagonist. The nonoccurrence $(00 \%)$ of existential processes suggests that the human interactant is in such a state of mind that there seem to exist no-one else and nothing in the world or at least in his environment.

\subsection{Detailed Analysis of Process Types, Participants and Circumstances in Extract 2}

The twenty-one material processes (making $28.37 \%$ of the total) include both Action processes and Event processes. However, there are very few Event processes; most of the twenty-one material processes are Action processes. For example, "Izongo groping" (clause 9), "Izongo graps at anything" 
(clause 10) and "you paddle round and round" (clause 14) are three of those Action processes. Having many more Action processes (than Event processes) in the text means that animate Actors are dominant. The two major animate Actors are Izongo in such clauses as 9, 10, 19 and "you" (the indefinite pronoun standing for any human being) in such clauses as 14, 15 and 41 . Only in clause 59 is Okolo assigned the role of Actor.

All the Action processes are Intention processes; none is Supervention. This suggests that the text is mostly concerned with a human participant under action, that is, Izongo, taking intentional actions. At the same time, the indefinite pronouns "you", "no-one" and "everyone" are assigned the role of Actor in an important number among the Action processes at stake. Thus the text under analysis shows both Izongo and any other human being referred to as "you / everybody", at work, trying no doubt to reach some goal(s). Some of the material processes in this extract (about 30\%) are middle, i.e. intransitive, others (about 70\%) are effective, i.e. transitive. "Groping", which is repeated in clauses 9 and 50, is one of the middle processes. The role of Actor is played in clause 9 by Izongo, suggesting that his goal, i.e. what he is looking for, is difficult to reach. In clause 50, the Actor role is rather assigned to "everybody". This extension of Actor role from Izongo to "everybody" suggests all the human actors' difficulty to reach their goals, if they know at all what they are looking for. "Paddle" in clause 14 is another middle process whose occurrence in this text is noteworthy. Here, the role of Actor is played by "you", meaning "human beings in general". They paddle not forward but "round and round". This Circumstance of manner ("round and round") further suggests that things happen on the same place without any progress, as it is difficult for the interactants to reach their goals. Interestingly, the Circumstance of manner "around", which is synonymous with "round and round", occurs in clause 50 to specify how the groping is done. This confirms the idea of lack of progress. The occurrence of the process of "sitting" in clause 59, which is also middle, with Okolo in the role of Actor, shows that the latter is not an exception when it comes to people's difficulty in finding their way out from the darkness they live in.

Concerning effective processes, we have such processes as "grabs" in clause 10, "guide" in clauses 17 and 19, "enter" in clauses 40, 41 and 44. In these processes, again, the role of Actor is distributed between Izongo on the one hand and, on the other hand, "you / another / no-one". In clause 10 where the process is "grabs", the Goal is "anything" ("anything that touches him"); that is the result of the process of groping mentioned above. By dint of groping with uncertainty, the Actor (Izongo) ends up grabbing anything he feels, which amounts to grabbing nothing with certainty. The Circumstance of cause "out of fear" proves how unsafe and uncertain the Actor feels. The process of guiding occurs once in clause 17 ("or you are guided by voices from the village") and twice in between clauses 19 and 22 as follows: "Izongo, lost in the fog, guides those who are also lost in the fog, and those in the village who, by their voices, want to guide him". One question we may ask ourselves, here, is: who actually plays the role of Actor when it comes to guiding? Is it Izongo, the voices, the voices from the village or both (Izongo and the voices) at a time? It is difficult to say; this suggests leadership confusion. The confusion will be but confirmed if one considers the Goal in each of those clauses containing the process "guide". So, although "guide" is an effective material process, it is not used in this context to clearly show who guides whom. Instead, the occurrence of the process of guiding in this interaction shows Izongo's incapacity of ruling his people properly. Regarding "enter", which occurs in clauses 40, 41 and 44, taken literally, it is a material process indeed. Then, the Goal in each of the three clauses is the same: "a person's inside". This particular process and the participants in it will, however, be discussed later.

As the table shows, Mental processes rank third in the extract, after Material and Relational processes. The percentage of Mentals (18.91\%) is quite significant as compared to the percentage of the other process types, which are all lower than $10 \%$. It means that the participants in the interaction are noticeably involved in mental actions: congniction, perception or affection. Here are four of those Mental processes:

- Maybe Izongo knows no meaning of life (clause 7)

- Maybe he (The Big One of Sologa) knows (clause 25)

- (You) knowing your purpose in this world (clause 66)

- As for him (Okolo), his purpose he knows (clause 71) 
The most dominant subtype is that of cognition, expressed with the process of "knowing" as can be seen in these selected four clauses. The role of Sensor is distributed among four (types of) participants: Izongo, The Big One of Sologa, You / One / People and Okolo. In most clauses under analysis, the recurrent Phenomenon is "meaning of life". Of course, this Phenomenon ("meaning of life") is ellipsed in the pair of clauses $25 / 26$ and in 27. It is referred to as "it" in 28 and replaced by "purpose" in clause 71. The devices of ellipsis and substitution do not preclude the Phenomenon "meaning of life" from having the value of a main issue discussed in the text.

The table of statistics shows $43.24 \%$ of Relational processes; that is quite important. The numerous Relationals include:

- What is their meaning of life? (clause 1)

- What is the meaning of life to Izongo? (clause 6)

- What is his [The Big One of Sologa's] meaning of life? (clause 24)

- And that is perhaps the root of the conflict (clause 39)

These four intensive Identifying processes, scattered at different stages of the text, show that this text concentrates on the meaning of life, i.e. the value or the sense of life, as the main topic. The Circumstance of matter "to Izongo" in clause 6 and the reference made of the Big One of Sologa in clause 24 suggest the variation of people's perception of the meaning of life. And "people", here, means not communities but individuals. That is shown by the occurrence of such possessive attributive processes as "No, they can't one meaning of life have" (clause 2), "Each one has his meaning of life" (clause 5) and "Yes, each one has a meaning of life to himself " (clause 38).

It is noteworthy that the inanimate participant in the possessive attributive process in clause 62 is "purpose": "everyone has or ought to have a purpose". This inanimate participant replaces "meaning of life" and is constantly repeated or referred to in many clauses: 64, 66, 67, 70, 71, 72 and 73. Such a participant substitution implies that the big question under consideration is every human being's purpose in this world, i.e. every human being's meaning of life, the reason for their existence in this world. And since people's perception of life varies a great deal from an individual to another, it becomes a philosophical issue, a hardly solvable question. Thus we can perfectly understand the relevance of the identifying Intensive process in clause 39, which does occur almost in the very center of the text: "And that is perhaps the root of the conflict".

\subsection{Discussion of Findings and Conclusion}

This investigation has looked into Transitivity patterns in two extracts from The Voice, a novel by the African (Nigerian) writer Gabriel Okara. So the analyses have been carried out from the point of view of Systemic Functional Linguistics, especially in the Hallidayan transitivity framework. The two excerpts under analysis have been named $\mathrm{E}_{1}$ and $\mathrm{E}_{2}$. In the above sections of analyses, each of the two extracts has been scrutinized separately for the identification and description of transitivity patterns. Here, in order to have a thorough discussion of the results, I find it almost indispensable to compare the data relating to both extracts.

The table of statistics has shown that there are many more material processes in $\mathrm{E}_{1}$ than in $\mathrm{E}_{2}: 72.64 \%$ versus $28.37 \%$. This suggests that there are more tangible actions of doing in $E_{1}$ than in $E_{2}$. Those numerous tangible actions are the author's realization of his ideology about a hectic world in which there is much ado for nothing. $E_{1}$ is meant to show man's daily frantic but vain quest of interests that are either avowed or unavowed. So is the whole novel, at least to some extent. Even the average proportion of material processes in $\mathrm{E}_{2}$ contributes to encoding that ideology.

Still regarding the material processes in $\mathrm{E}_{1}$, the transitivity labelling of some of them is debatable.

For instance, consider:

- $\quad$ and he his thoughts picked in his inside (clause 12)

- The picked thoughts then drew his leg (clause 15)

- His thoughts in his inside began to fly in his inside darkness (clause 18) 
- Then the flying thoughts drew his hand (clause 19)

- and his head expanded (clause 55)

Considering "pick" at first sight and in the literal meaning, it is a material process. Taking clause 12 as a material process implies that "he" is Actor and "his thoughts" is Goal. Materially, the process of "picking" cannot agree with one's thoughts as Goal. So, the process in clause 12 is actually not a material one. Now, taking it as a mental process, we shall label "he" as Senser and "his thoughts" as Phenomenon. What mental process subtype is it then? Cognitive, perceptive or affective? Referring to the Phenomenon "his thoughts", we can definitely rate this process of picking as a special cognitive mental process. In the same way, physically, "draw" is material and in clause 15 "his leg" would be labelled as the Goal of the process of drawing. However, "The picked thoughts" is not physical and it cannot agree with the process-Goal sequence "draw someone's leg". So, the process in clause 15 is not material but a mental process. Then, one has to decide which of the two participants ("The picked thoughts" and "his leg") is Senser and which one is Phenomenon. No matter the decision that may be made, basing on the presence of the participant "The picked thought" here, we can eventually rate the process of drawing as a special cognitive mental process. The same goes for the processes of drawing in clause 19 and flying in clause 18. In clause 55, the process of expanding cannot be seen as a physical action; so it is not to be considered as a material process. Instead, it can be felt by the one whose head has "expanded". Thus, rather than considering "expand" as a material process where "his head" is Actor, it should be taken as a mental, with "his head" in the role of Senser. Of course, the real Senser is the interactant whose head has expanded.

All the processes that have just been discussed do look or sound material but they do not happen in the physical world. They take place in the mind of an interactant. So, they are particular mental processes, especially cognitive ones. Their occurrence suggests the seriousness of the topic of the text as an intellectual concern. It is a foregrounding of human cognitive dimension. Added to the other mental processes in the interaction, they show that the main interactant, Okolo, is mentally drowned. Such mental drowning can further be understood as an expression of the limits of man's cognitive qualities in some circumstances.

The striking gap between the rates of relational processes in $\mathrm{E}_{1}(05.66 \%)$ and in $\mathrm{E}_{2}(43.24 \%)$ implies that there is much less room in $\mathrm{E}_{1}$ for identifying participants' values or describing them than in $\mathrm{E}_{2}$. Looking closely into the clauses containing this process type which predominates in $E_{2}$, it has been noticed that the direct participants functioning as Token / Value or Carrier / Attribute are "people", "the meaning of life" and "purpose". Indeed, life is so full of surprises, paradoxical things and, sometimes, mysterious happenings that it is rather difficult to grasp its meaning and people's purpose when they come to live in this world. Seeking to know the meaning of life and what people live for, is but a vain and even pretentious task. There is no wonder, therefore, that Okolo's search is doomed to failure and that the so-called hero is rather seen as abnormal, worth ostracizing and even "crucifying". Thus, from the extracts analyzed in this paper, one can maintain that the absurd side of this world is the overall ideology encoded in The Voice by Gabriel Okara.

\section{REFERENCES}

[1] Amoussou, Y. C. (2015). Mood, Interpersonal and Ideational Meaning Patterns in the Abiku poems (J.P. Clark; W. Soyinka). International Journal of language and Linguistics, 2(3).

[2] Anozie, S. O. (1965). The theme of alienation and commitment in Okara's The Voice. The Bulletin of the Association for African Literature in English, $\mathrm{N}^{\circ} 3$.

[3] Ashaolu, A. O. (1979). A voice in the wilderness: the predicament of the social reformer in Okara's The Voice. The International Fiction Review, 6 (2), 111-117.

[4] Ayoola, M. (2013). Interpersonal and Ideational Metafunctions of Selected Political Advertisements in some Nigerian Newspapers. International Journal of Humanities and Social Science, 3(8), 165-178.

[5] Berry, M. (1977). Introduction to Systemic Linguistics: Structures and Systems. Vol. 1. London: Batsford.

[6] Bloor, T. and Bloor, M. (1995). The functional analysis of English: a Hallidayan approach. London: Macmillan.

[7] Boukari, N. (2015). "An Inquiry into the Impact of Contextual Features on Ideational and Interpersonal Meanings in Flora Nwapa's Selected Novels". Unpublished PhD Thesis. UAC. 
[8] Eggins, S. (1994/2011). An Introdution to Systemic Functional Linguistics (2nd ed). Manchester, Great Britain: Continuum.

[9] Fontaine, L. (2013). Analysing English Grammar: A systemic Functional Introduction. New York: Cambridge University Press.

[10] Fowler, R. (1986). Linguistic Cristicism. London: Oxford University Press.

[11] Halliday, M. A. K. \& Hasan, R. (1985). Language, context and text: aspect of language in a socialsemiotic perspective. Oxford: Oxford University Press.

[12] Halliday, M. A. K. \& Matthiessen, Ch. (2004). An Introduction to Functional Grammar (3rded.) London: Hodder Education, and Hachette UK Company.

[13] Halliday, M. A. K. \& Matthiessen, Ch. (2006). Construing Experience through Meaning: A languagebased Approach to Cognition. London - New York: Continuum.

[14] Halliday, M. A. K. (1971). Linguistic function and literary style: An inquiry into the language of William Golding's The Inheritors. In S.B. Chatman (Ed.), Literary Style. London and New York: Oxford University Press.

[15] Halliday, M. A. K. (1976). System and Function in Language. Ed. G. Kress. London: Oxford University Press.

[16] Halliday, M. A. K. (1985). Introduction to Functional Grammar. London: Edward Arnold.

[17] Hasan, R. (1989). Linguistics, language, and verbal art. Oxford: Oxford University Press.

[18] Iwamoto, N. (2007). Stylistics and Linguistic Analysis of Literary Text Using Systemic Functional Grammar. Departemental Bulletin Paper, 61-96.

[19] Kies, D. (1992). The Uses of Passivity: Suppressing Agency in Nineteen Eighty-four, in M. Davies and L. Ravelli (eds.): 12-14.

[20] Koussouhon, A. L. (2009a). Reassessing the language of "Abiku" (John Pepper Clark; Wole Soyinka): A systemic Functional Analysis. Liberal Forum: An Academic Journal, Vol $3 \mathrm{~N}^{\circ}$ s 1\&2, pp 150-175.

[21] Koussouhon, A. L. (2009b). Process types and Ideational Meanning in The Beautiful Ones Are Not Yet Born, in IMO-IRIKISI, Vol1, pp 129-142.

[22] Koussouhon, L. \& Allagbé, A. (2013). The Lexico-grammar of Chimamanda Ngozi Adichie's fiction: A systemic functional contribution. Language \& Devenir, (22), 19-44.

[23] Koussouhon, L. \& Dossoumon, A. (2014). Lexico-grammatical Analysis of Yellow-Yellow by Kaine Agary: Focus on Experiential and Textual Meanings. Mediterranean Journal of Social Sciences, 5 (23), 2430-2438.

[24] Koussouhon, L. \& Dossoumou, A. (2015). Exploring Ideational Metafunction in Helon Habila's Oil on Water: A re-evaluation and redefinition of African Women's Personality and Identity through Literature. International Journal of Applied Linguistics and English Literature, 4(5), 129-136.

[25] Obiechina, E. (1972). Art and Arifica in Okara's The Voice. Okike, 1(3), 23-33.

[26] Okara, G. (1964). The Voice. London: Heinemann Educational Book Ltd.

[27] Palmer, E. (1972). An Introduction to the African Novel. London: Heinemann.

[28] Scott, P. (1990). Gabriel Okara's The Voice: the non-Ijo reader and Pragmatics of translingualism. Research in African Literature, 21, 75-88.

[29] Simpson, P. (1993). Language, Ideology and Point of View. London: Routledge.

[30] Thumboo, E. (1986). Language as power: Gabriel Okara's The Voice as a paradigm. World Englishes, 5, 249-264.

\section{Appendix: The Extracts under Analysis}

\section{Excerpt 1}

When Okolo ${ }^{1}$ came to know himself, he ${ }^{2}$ was lyingon a floor, on a cold floor ${ }^{3}$ lying. He ${ }^{4}$ opened his eyes ${ }^{5}$ to see but nothing he ${ }^{6}$ saw, nothing he ${ }^{7}$ saw. For the darkness ${ }^{8}$ was evil darkness and the outside night ${ }^{9}$ was black black night. Okolo ${ }^{10}$ lay still in the darkness ${ }^{11}$ enclosed by darkness, and he his thoughts ${ }^{12}$ picked in his inside. Then his picked thoughts his eyes ${ }^{13}$ opened but his vision only ${ }^{14}$ met a rock-like darkness. The picked thoughts then ${ }^{15}$ drew his legs but his legs ${ }^{16}$ did not come. They ${ }^{17}$ were as heavy as a canoe full of sand. His thoughts in his inside ${ }^{18}$ began to fly in his inside darkness like frightened birds hither, thither, homeless. Then the flying thoughts ${ }^{19}$ drew his hand but the hands ${ }^{20}$ did not belong to him, it seemed. So Okolo on the cold cold floor ${ }^{21}$ lay with his body as soft as an over-pounded foo foo. So Okolo ${ }^{22}$ lay with eyes open wide in the rock-like darkness ${ }^{23}$ staring, staring. 
Okolo for years and years ${ }^{24}$ lay on the cold cold floor at the rock-like darkness ${ }^{25}$ staring. Then suddenly he ${ }^{26}$ saw a light. $\mathrm{He}^{27}$ drew his feet with all his soul and his feet ${ }^{28}$ came. $\mathrm{He}{ }^{29}$ drew his hands and his hands ${ }^{30}$ came. He ${ }^{31}$ stood up with his eyes on the light and ${ }^{32}$ walked towards the light. As he ${ }^{33}$ moved towards the light, the light also ${ }^{34}$ moved back. He ${ }^{35}$ moved faster and the light also ${ }^{36}$ moved faster back. Okolo ${ }^{37}$ ran and the light also ${ }^{38}$ ran. Okolo ${ }^{39}$ ran, the light ${ }^{40}$ ran. Okolo ${ }^{41}$ ran and ${ }^{42}$ hit a wall with his head. Okolo ${ }^{43}$ looked and the light ${ }^{44}$ was no more. He then ${ }^{45}$ stretched his hands forth and ${ }^{46}$ touched the wall. His fingers ${ }^{47}$ felt dents and holes. Okolo ${ }^{48}$ walked sideways like a crab with his fingers on the wall ${ }^{49}$ feeling dents and holes, dents and holes in the rock-like darkness until his feet ${ }^{50}$ struck an object. As Okolo ${ }^{51}$ stopped and ${ }^{52}$ felt the object his body ${ }^{53}$ became cold. His heartbeat ${ }^{54}$ echoed in the rock-like darkness and his head ${ }^{55}$ expanded. Still, he ${ }^{56}$ felt along the object until his fingers ${ }^{57}$ went into two holes. As his fingers ${ }^{58}$ went into the holes he quickly ${ }^{59}$ withdrewthem and ${ }^{60}$ ran. He ${ }^{61}$ ran and ${ }^{62}$ fell, ${ }^{63}$ ran and ${ }^{64}$ fell over other objects. He ${ }^{65}$ ran and ${ }^{66}$ knocked against the wall and ${ }^{67}$ fell. Still he ${ }^{68}$ ran, then suddenly ${ }^{69}$ stopped. He ${ }^{70}$ saw a light in front of him. He ${ }^{71}$ moved gently ${ }^{72}$ crouching forward like a hunter ${ }^{73}$ stalking game. Then when he nearly ${ }^{74}$ reached the light he ${ }^{75}$ rushed forward.

Okolo ${ }^{76}$ found himself ${ }^{77}$ standing in daylight in a street, hither and thither ${ }^{78}$ turning his eyes. He ${ }^{79}$ stood ${ }^{80}$ turning his eyes this way and that way in the street. Thus he ${ }^{81}$ stood with the crowd ${ }^{82}$ passing him by: cars ${ }^{83}$ honking, people ${ }^{84}$ shouting, people ${ }^{85}$ dying, women ${ }^{86}$ delivering, beggars ${ }^{87}$ begging for alms, people ${ }^{88}$ feasting, people ${ }^{89}$ crying, people ${ }^{90}$ laughing, politicians [with grins that ${ }^{91}$ do not reach their insides] ${ }^{92}$ begging for votes, priests ${ }^{93}$ building houses, people ${ }^{94}$ doubting, people ${ }^{95}$ marrying, people ${ }^{96}$ divorcing, priests ${ }^{97}$ turning away worshippers, people ${ }^{98}$ hoping (), hopes ${ }^{99}$ breaking plate-like on cement floors. Thus Okolo ${ }^{100}$ stood ${ }^{101}$ watching the crowd ${ }^{102}$ pass him by until he ${ }^{103}$ saw a constable ${ }^{104}$ approaching with eyes that nothing ${ }^{105}$ saw and feet that ${ }^{106}$ did not touch the ground.

From The Voice, pp. 76-78

\section{Excerpt 2}

What ${ }^{1}$ is their meaning of life? No, they ${ }^{2}$ can't one meaning of life have. ${ }^{3}$ Each man to one meaning of life; ${ }^{4}$ each woman to one meaning of life. Each one ${ }^{5}$ has his meaning of life. What ${ }^{6}$ is the meaning of life to Izongo? Maybe Izongo ${ }^{7}$ knows no meaning of life. Maybe he ${ }^{8}$ is in darkness ${ }^{9}$ groping and ${ }^{10}$ grabs out of fear at anything that ${ }^{11}$ touches him. Many there ${ }^{12}$ are like Izongo with no sense of direction like you ${ }^{13}$ are in a fog in a river. You ${ }^{14}$ paddle round and round or ${ }^{15}$ go in the opposite direction until the fog ${ }^{16}$ clears or you ${ }^{17}$ are guided by voices from the village. The difference only is that Izongo ${ }^{18}$ lost in the fog ${ }^{19}$ guides those who ${ }^{20}$ are also lost in the fog, and those in the village who, by their voices, ${ }^{21}$ want to ${ }^{22}$ guide him.

${ }^{23}$ How about the Big One of Sologa? What ${ }^{24}$ is his meaning of life be? Maybe he ${ }^{25}$ knows, maybe he ${ }^{26}$ does not. Maybe he ${ }^{27}$ knows but ${ }^{28}$ sees it in a mirror and what he ${ }^{29}$ sees ${ }^{30}$ is himself. ${ }^{31}$ And the Whiteman, the superintendent of the listeners? $\mathrm{He}^{32}$ is no different. Only his skin ${ }^{33}$ is white. $\mathrm{He}^{34}$ was surprised that somebody like him, Okolo, ${ }^{35}$ could be in search of it. Maybe the whiteman's father ${ }^{36}$ did not teaching words say to him as his father ${ }^{37}$ had said to him.

Yes, each one ${ }^{38}$ has a meaning of life to himself. And that ${ }^{39}$ is perhaps the root of the conflict. No one ${ }^{40}$ can enter another's inside. You ${ }^{41}$ try to enter and you ${ }^{42}$ are kicked out at the door. You ${ }^{43}$ allow another ${ }^{44}$ to enter your inside and ${ }^{45}$ see everything in it, you ${ }^{46}$ are regarded as one without a chest or as one who nothing ${ }^{47}$ knows... Maybe he ${ }^{48}$ is wrong. There ${ }^{49}$ may be only one meaning in life and everybody ${ }^{50}$ is just groping along in their various ways ${ }^{\mathbf{5 1}}$ to achieve it like religion - Christians, Moslems, Animists - all ${ }^{52}$ trying to reach God in their various ways. What ${ }^{53}$ is he himself trying to reach? For him it ${ }^{54}$ has no name. Names ${ }^{55}$ bring divisions ${ }^{56}$ and divisions, strife. So ${ }^{57}$ let it be without a name; ${ }^{58}$ let it be nameless...

So Okolo for three days and three nights ${ }^{59}$ sitting with his knees drawn to his chin, ${ }^{60}$ talked in his inside and in the end ${ }^{61}$ agreed with his inside that everybody ${ }^{62}$ has or ought to have a purpose apart from ${ }^{63}$ bearing children and the sweetness of one's inside in the world ${ }^{64}$ is in the fulfillment of that purpose. The only hard thing, rather one of the two hard things, ${ }^{65}$ is $\left[{ }^{66}\right.$ knowing your purpose in this world]. The other which ${ }^{67}$ is harder, ${ }^{68}$ is not to corrupt it after ${ }^{69}$ knowing what your purpose ${ }^{70}$ is. As 
for him, his purpose he ${ }^{71}$ knows. He ${ }^{72}$ will keep it clean as a virgin sheet of white paper. And ${ }^{73}$ to keep it so clean, he ${ }^{74}$ will keep his inside as clean as the sky.

From The Voice, pp. 111-112

\section{AUTHOR'S BIOGRAPHY}

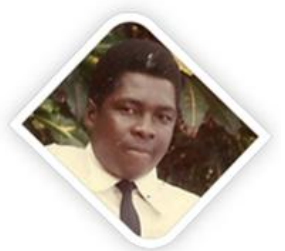

Nouréni Boukari is a $\mathrm{PhD}$ in Applied Linguistics, especially Systemic Functional Linguistics. He is an Assistant Lecturer at the University of Parakou, Benin.

Léonard A. Koussouhon is Full Professor (CAMES) of Applied Linguistics and African Anglophone Literature.

Citation: Nouréni Boukari, Léonard A. Koussouhon. "Transitivity Analysis of Gabriel Okara's The Voice" International Journal on Studies in English Language and Literature (IJSELL), vol 6, no. 4, 2018, pp. 1-15. doi:http://dx.doi.org/10.20431/2347-3134.0604001.

Copyright: (c) 2018 Authors. This is an open-access article distributed under the terms of the Creative Commons Attribution License, which permits unrestricted use, distribution, and reproduction in any medium, provided the original author and source are credited. 